\title{
Anaerobic animals from an ancient, anoxic ecological niche
}

Marek Mentel ${ }^{1}$, William Martin ${ }^{2^{*}}$

\begin{abstract}
Tiny marine animals that complete their life cycle in the total absence of light and oxygen are reported by Roberto Danovaro and colleagues in this issue of BMC Biology. These fascinating animals are new members of the phylum Loricifera and possess mitochondria that in electron micrographs look very much like hydrogenosomes, the $\mathrm{H}_{2}$-producing mitochondria found among several unicellular eukaryotic lineages. The discovery of metazoan life in a permanently anoxic and sulphidic environment provides a glimpse of what a good part of Earth's past ecology might have been like in 'Canfield oceans', before the rise of deep marine oxygen levels and the appearance of the first large animals in the fossil record roughly 550-600 million years ago. The findings underscore the evolutionary significance of anaerobic deep sea environments and the anaerobic lifestyle among mitochondrion-bearing cells. They also testify that a fuller understanding of eukaryotic and metazoan evolution will come from the study of modern anoxic and hypoxic habitats.
\end{abstract}

\section{Commentary}

The newly reported tiny marine animals that complete their life cycle in the total absence of light and oxygen are members of the phylum Loricifera, a phylum discovered less than 30 years ago, and they are less than a millimetre in size [1]. They were collected from a deep basin at the bottom of the Mediterranean Sea, where they inhabit a nearly salt-saturated brine that, because of its density $\left(>1.2 \mathrm{~g} / \mathrm{cm}^{3}\right)$, does not mix with the waters above. As a consequence, this environment is completely anoxic and, due to the activity of sulphate reducers, contains sulphide at a concentration of $2.9 \mathrm{mM}$. Despite such harsh conditions, this anoxic and sulphidic environment is teeming with microbial life, both chemosynthetic prokaryotes that are primary producers [2], and a broad diversity of eukaryotic heterotrophs at the next trophic level $[3,4]$. That this ecological niche also supports animals is a surprise that poses all sorts of interesting questions. Despite being unexpected, however, the finding ties together recent developments from several independent fields (marine biology, cell biology, evolutionary theory and geochemistry) that all point to the evolutionary significance of eukaryotic life in anaerobic environments.

\footnotetext{
* Correspondence: w.martin@uni-duesseldorf.de

${ }^{2}$ Institute of Botany III, University of Düsseldorf, 40225 Düsseldorf, Germany
}

The first question raised is 'how?'. How is it possible that animals can inhabit this anoxic and sulphidic environment? This might seem impossible to some, after all one often reads that 'animals have an absolute requirement for oxygen' [5] or 'sulphide is poisonous' [6]. However, not all animals are strictly dependent upon oxygen. Some use different terminal electron acceptors other than oxygen in their mitochondrial respiratory chains, most commonly fumarate, leading to the excretion of succinate and propionate [7], often accompanied by acetate excretion as well [8]. Since the mechanism of sulphide toxicity to animals entails the inhibition of cytochrome $c$ oxidase [9], mitochondria that are not dependent upon that final mediator of an electron transfer to $\mathrm{O}_{2}$ also do not have such a problem with sulphide. Among animal lineages, facultative anaerobic mitochondria have been studied from various free living invertebrates, including the oyster Mytilus (Mollusca) [10], the peanut worm Sipunculus (Sipuncula) [11] or the polychaete worm Arenicola (Annelida) [12] and parasites like Fasciola (Platyhelminthes) [13] and Ascaris (Nematoda) [14]. However, such oxygen-independent energy metabolism in animals is often restricted to some stages - albeit sometimes prolonged - of the lifecycle. The Loriciferans that Danovaro et al. [1] describe spend their entire life cycle in the sediment: what was once seen as an 'absolute requirement' for $\mathrm{O}_{2}$ among 
animals should now be seen as a lineage-specific preference, albeit it one that is very pronounced, especially among those animals that, like ourselves, live on land, permanently above the soil line.

\section{Anaerobic mitochondria: more common all the time}

A look at the phylogenetic distribution of characterized anaerobic mitochondria among animal lineages shows that these are not clustered but spread across metazoan phylogeny (Figure 1). Are these recent adaptations to anaerobic habitats or are they holdovers from our more distant evolutionary past? The biochemistry and the enzyme equipment used in the facultatively anaerobic mitochondria of metazoans is nearly identical across lineages [7,10-15], strongly indicating a common origin from the metazoan ancestor that might have lived some 600 million years (MY) ago [16]. The examples in Figure 1 cover both the Lophotrochozoa and the Ecdysozoa, where the newly-described Loricifera with their distinctive organelles belong. Although no biochemical data are yet available for these intriguing new Loriciferan mitochondria, from the electron micrographs presented by Danovaro et al. [1] the organelles look like hydrogenosomes - anaerobic forms of mitochondria that generate $\mathrm{H}_{2}$ and adenosine triphosphate (ATP) from pyruvate oxidation [17] and which were previously found only in unicellular eukaryotes. Danovaro et al. [1] also report that the animals harbour structures resembling prokaryotic endosymbionts, reminiscent of the methanogenic endosymbionts found in some hydrogenosome-bearing protists; fluorescence of $\mathrm{F}_{420}$, a typical methanogen cofactor [18], or lack thereof, will bring more insights as to what these structures are.

If we follow the anaerobic lifestyle further back into evolutionary history (Figure 2), beyond the origin of the metazoans, we see that the phylogenetic distribution of eukaryotes with facultative anaerobic mitochondria, eukaryotes with hydrogenosomes and eukaryotes that possess mitosomes (reduced forms of mitochondria with no direct role in ATP synthesis [19]) shows a similar picture to that seen for animals. In all six of the major lineages (or supergroups) of eukaryotes that are currently recognized [20], forms with anaerobic mitochondria have been found [21]. The newest additions to the growing collection of anaerobic mitochondrial metabolisms are the denitrifying foraminiferans $[22,23]$. For this group, the underlying enzymes also have yet to be worked out. However, for the remainder of the eukaryotes summarized in Figure 2, a handful of about a dozen enzymes make the difference between a 'normal' (in the sense of 'familiar from older college textbooks') $\mathrm{O}_{2}$-respiring mitochondrion found in mammals, and the energy metabolism of eukaryotes with anaerobic mitochondria, hydrogenosomes or mitosomes $[7,19,21,24]$.
Notably, the full complement of those enzymes, once thought to be specific to eukaryotic anaerobes, surprisingly turned up in the green alga Chlamydomonas reinhardtii [24], which produces $\mathrm{O}_{2}$ in the light, has typical $\mathrm{O}_{2}$-respiring mitochondria but, within about $30 \mathrm{~min}$ of exposure to heterotrophic, anoxic and dark conditions, expresses its anaerobic biochemistry to make $\mathrm{H}_{2}[25,26]$ in the same way as trichomonads, the group in which hydrogenosomes were discovered [17]. Thus, Chlamydomonas provides evidence which indicates that the ability to inhabit oxygen-harbouring, as well as anoxic environments, is an ancestral feature of eukaryotes and their mitochondria; in that sense it is a true missing link that unites mitochondria like our own and those from the anoxic world [19].

It is not yet known what role, if any, the mitochondria of the newly discovered loriciferans play in the energy metabolism of those animals and, unfortunately, the same is true for the myriad of fascinating eukaryotic protists that inhabit the very same environment where the anoxic loriciferans were found. In a series of recent papers, Stoeck and colleagues have surveyed the protistan diversity from L'Atalante and similar habitats with environmental sequencing and metagenomic techniques $[3,4,27]$. Those reports lead to a wealth of representatives from many of the same groups shown in Figure 2 being uncovered: ciliates, fungi and chromalveolates, in addition to representatives of many other eukaryotic groups, including the choanoflagellates [3], which are regarded as the unicellular sisters to the metazoan clade. The investigation of anaerobic mitochondria remains an area of rapid progress and it will be a challenge to discover what those mitochondria are doing in real-life anoxic and hypoxic environments, which are very widespread among modern habitats [28] and where eukaryotic anaerobes abound [27].

\section{Evolutionary significance?}

What is the evolutionary significance of the new findings? The L'Atalante basin has been anoxic for only about 50,000 years [1] but have all of its microbial and metazoan inhabitants only recently adapted to life in anoxic conditions during that time? Hardly. Nobody seriously considers that anaerobic prokaryotes dwelling in such anaerobic habitats, such as methanogens and sulphate reducers, have only recently adapted to anaerobic niches. The prokaryote inhabitants have existed for well over a billion years, and have reached this new habitat by dispersal, not by adaptive evolution de novo and in situ. Indeed, geochemical evidence has shown that methanogenesis and sulphate reduction, and the niches in which they occur, are truly ancient $[29,30]$. (For marine environments, dispersal is not a fundamental problem because, despite vast distances, similar types of 

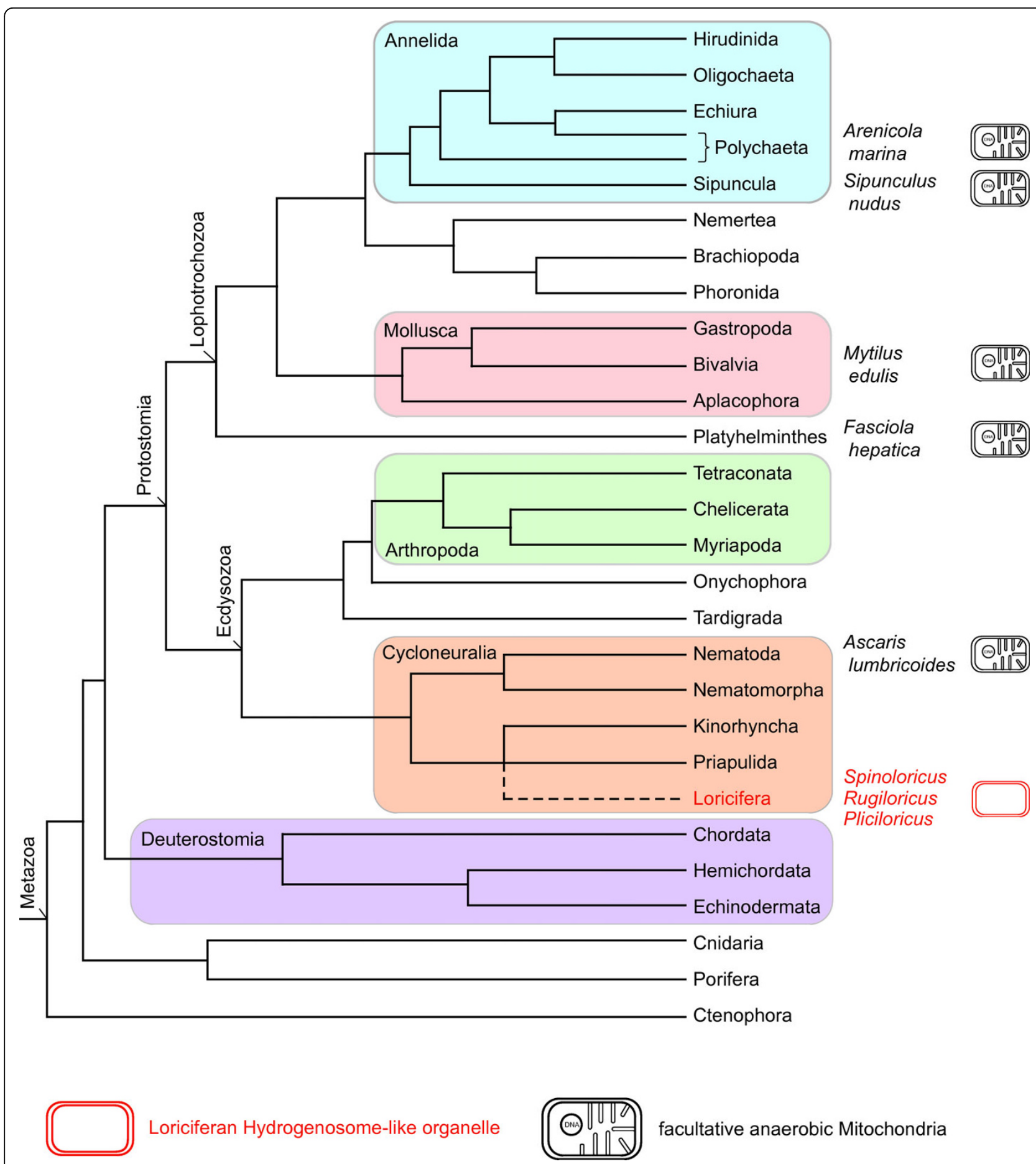

Figure 1 Schematic phylogeny of animals based on the report by Dunn et al [48] which, however, did not include the phylum Loricifera [1] (highlighted in red). It was placed here (dotted line) as branching with Priapulida and Kinorhyncha as reported elsewhere [49,50]. Higher taxon designations are those used in references [48-50]. The Cycloneuralia, where Loricifera belong, are currently grouped within the Ecdysozoa, which also includes nematodes and insects. To the right of the phylogeny, several species are listed whose facultatively anaerobic mitochondria have been studied [10-14]; in no way does this imply the absence of anaerobic mitochondira in other groups. No biochemical data are yet available for the Loriciferan mitochondria [1]. 


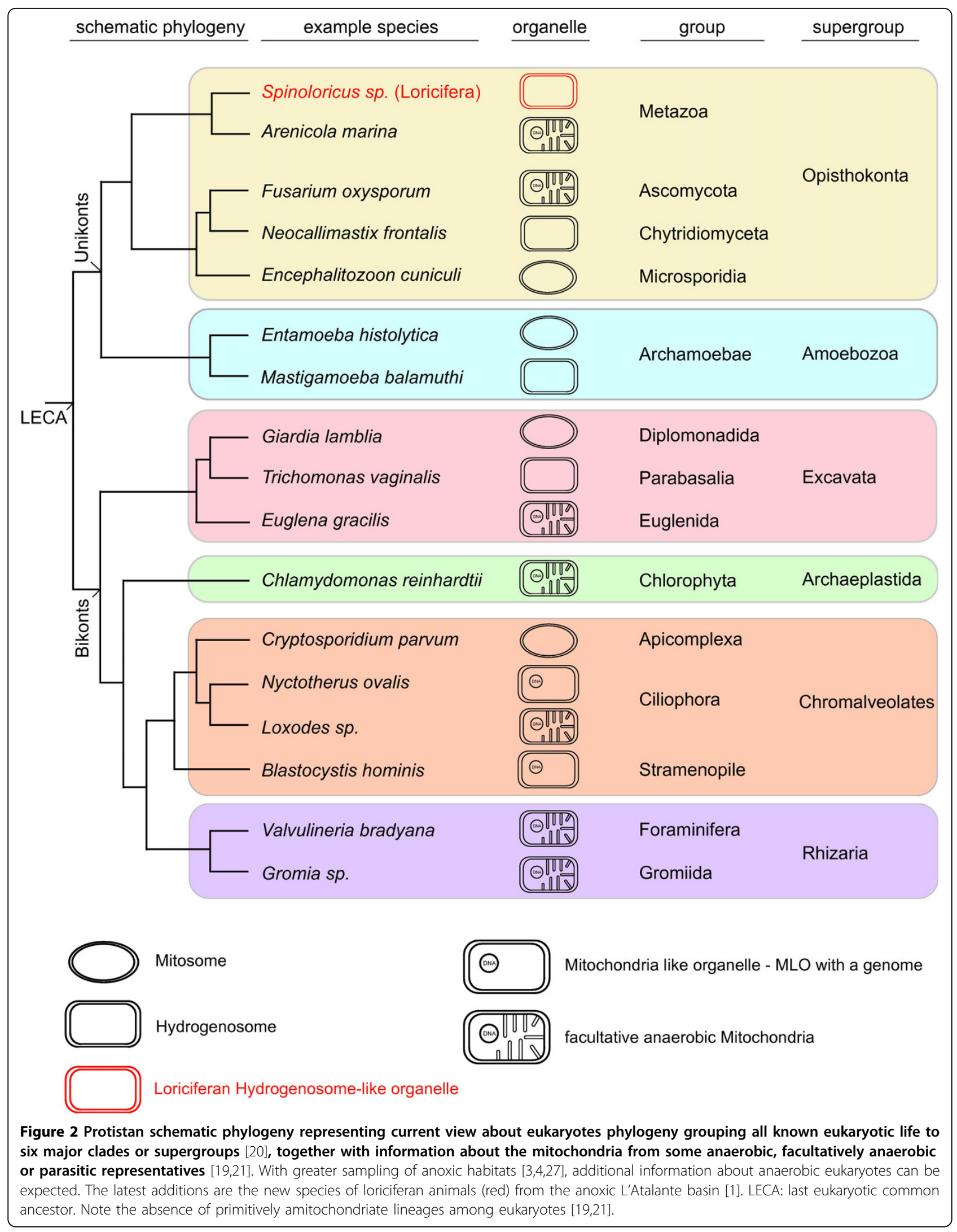


seafloor habitats often harbour similar communities, from microbes to large animals [31]). However, when it comes to eukaryotes, there is still a curious tendency to assume that eukaryotes only invaded anaerobic niches of late. Perhaps this stems from a tendency (latently anthropocentric, no doubt) to view mitochondria as obligately $\mathrm{O}_{2}$-dependent organelles with the anaerobic forms of mitochondria being rare exceptions, even though the data (for example in Figures 1 and 2 or elsewhere $[7,8,17,19,21])$ tell us otherwise. In environments such as the L'Atalante basin, 'normal', $\mathrm{O}_{2}$-dependent mitochondria are the rare exception, if they exist at all, but eukaryotes abound [1,3,4,32,33]. Hence, further study of mitochondria from such environments should be revealing. That, however, is easier said than done, since, as seen in the present study [1] as in other work on organisms from anoxic marine sediments [32], a considerable effort has to be invested in order just to demonstrate that the organisms are even alive and not just sunken carcasses. Work on organisms from these environments poses substantial technical challenges, making every new insight all the more exciting.

While Danovaro et al. opt for the term 'enigmatic' in discussing the evolutionary significance of their findings, we have a decidedly different view. Given that anaerobic forms of mitochondria are widespread throughout the eukaryotic world, we see eukaryotes in anaerobic habitats as evidence for evolution in the Darwinian sense of descent with modification, with the traits that support survival in anaerobic environments having been conserved from earlier phases of Earth's history. This view is underpinned by what geologists and geochemists have been trying to tell biologists over the last 10 years about the prevalence of anoxic and sulphidic environments during the early phase of eukaryotic and metazoan evolution, but with the biologists perhaps not taking as much notice as they should.

\section{The bigger picture: add geological time}

What are the geologists trying to tell us about anoxic and sulphidic marine habitats? A readable summary of about 10 year's progress is given in three papers [34-36]. In a nutshell, the geologists are saying that the rise in atmospheric oxygen some 2.4 billion years ago is one thing, but that the oxygen levels in the ocean, where evolution was taking place, is quite another. Several lines of isotope evidence indicate that deep ocean waters were not fully oxygenated until about $580 \mathrm{MY}$ ago, about the time when the first large animals made their fossil debut. The reason for this anoxia, they say, has to do with high levels of sulphide in marine environments, from the workings of sulphate reducers [36], themselves strict anaerobes. The message for biologists is that the
Earth's oceans appear to have been largely anoxic and sulphidic (like the L'Atalante basin, but not hypersaline) below the photic zone (the upper about $200 \mathrm{~m}$ ) [34,36] and, possibly, also in the lower photic zone [35] for the time spanning roughly 1.8 billion years ago to about the beginning of the Cambrian period $560 \mathrm{MY}$ ago. That was the time during which eukaryotes arose and diversified [21]. Hence, it should hardly be surprising that the anaerobic lifestyle is widespread among eukaryotic lineages, right up into the animals [37]. One view is that the oxygenation of deep environments allowed the animals to become larger [38], which is different from saying that oxygen might in any way be causal to the Cambrian appearance of diverse animal forms [39]. Geologists have not been trying to hide their perspective from us biologists [40-42], nor have we biologists been trying to hide our progress in understanding eukaryotic anaerobes [21,43-46]. However, it seems that it will still take some time for a new default view of deep marine environments in the Late Precambrian - a new synthesis of sorts - to be accepted by biologists. The scenario is one of widespread anoxic and sulphidic habitats, almost certainly (in our view) teeming with little eukaryotic creatures, all with their mitochondria well suited to life with little or no oxygen [37] and all more or less like the ones we see in anoxic and sulphidic environments today. Such environments staged and witnessed the origin of evolution's greatest early inventions [47] and the new insights emerging from them deserve our close attention.

\section{Abbreviations}

ATP: adenosine triphosphate; MY: million years.

\section{Acknowledgements}

MM and WM thank the Deutsche Forschungsgemeinschaft (DFG) and WM is grateful to the European 'Research Council (ERC) for their financial support.

\section{Author details}

${ }^{1}$ Department of Biochemistry, Faculty of Natural Sciences, Comenius University, Mlynská dolina CH-1, 84215 Bratislava, Slovakia. ${ }^{2}$ Institute of Botany III, University of Düsseldorf, 40225 Düsseldorf, Germany.

Received: 16 March 2010 Accepted: 6 April 2010 Published: 6 April 2010

\section{References}

1. Danovaro R, Dell' Anno A, Pusceddu A, Gambi C, Heiner I, Kristensen RM: The first metazoa living in permanently anoxic coditions. BMC Biology 2010, 8:30.

2. Yakimov MM, La Cono V, Denaro R, D'Auria G, Decembrini F, Timmis KN, Golyshin PN, Giuliano L: Primary producing prokaryotic communities of brine, interface and seawater above the halocline of deep anoxic lake L'Atalante, Eastern Mediterranean Sea. ISME J 2007, 1:743-755.

3. Alexander E, Stock A, Breiner HW, Behnke A, Bunge J, Yakimov MM, Stoeck T: Microbial eukaryotes in the hypersaline anoxic L'Atalante deepsea basin. Environmental Microbiol 2009, 11:360-381.

4. Edgcomb V, Orsi W, Leslin C, Epstein SS, Bunge J, Jeon S, Yakimov MM Behnke A, Stoeck T: Protistan community patterns within the brine and halocline of deep hypersaline anoxic basins in the eastern Mediterranean Sea. Extremophiles 2009, 13:151-167. 
5. Canfield DE, Poulton SW, Narbonne GM: Late-Neoproterozoic deep-ocean oxygenation and the rise of animal life. Science 2007, 315:92-95.

6. Grieshaber M, Volkel S: Animal adaptations for tolerance and exploitation of poisonous sulfide. Ann Rev Physiol 1998, 60:33-53.

7. Tielens AGM, Rotte C, van Hellemond JJ, Martin W: Mitochondria as we don't know them. Trends Biochem Sci 2002, 27:564-572.

8. Tielens AGM, van Grinsven K, Henze K, van Hellemond J, Martin W: Acetate formation in the energy metabolism parasitic helminths and protists. Int J Parasitol 2010, 40:387-397.

9. Cooper CE, Brown GC: The inhibition of mitochondrial cytochrome oxidase by the gases carbon monoxide, nitric oxide, hydrogen cyanide and hydrogen sulfide: chemical mechanism and physiological significance. J Bioenergetics Biomembranes 2008, 40:533-539.

10. de Zwaan A: Molluscs. Metazoan Life Without Oxygen London: Chapman and HallBryant C 1991, 186-217.

11. Grieshaber M, Hardewig I, Kreutzer U, Pörtner H-O: Physiologial and metabolic responses to hypoxia in invertebrates. Rev Physiol Biochem Pharmacol 1994, 125:143-147.

12. Theissen $U$, Martin $W$ : Sulfide:quinone oxidoreductase (SQR) from the lugworm Arenicola marina shows cyanide- and thioredoxin-dependent activity. FEBS J 2008, 257:1131-1139.

13. van Hellemond JJ, Klei van der A, van Weelden SW, Tielens AG: Biochemical and evolutionary aspects of anaerobically functioning mitochondria. Phil Trans Roy Soc London Series B 2003, 358:205-213.

14. Barrett J: Parasitic helminths. Metazoan Life Without Oxygen London: Chapman and Hall, LondonBryant C 1991, 146-164

15. Tielens AGM, van Hellemond JJ: Anaerobic mitochondria: properties and origins. Origin of Mitochondria and Hydrogenosomes Berlin: SpringerVerlagMartin W, Müller M 2007, 85-104.

16. Peterson KJ, Cotton JA, Gehling JG, Pisani D: The Ediacaran emergence of bilaterians: congruence between the genetic and the geological fossil records. Phil Trans Roy Soc London Series B 2008, 363:1435-1443.

17. Müller M: The hydrogenosome. J General Microbiol 1993, 139:2879-2889.

18. Cheeseman $\mathrm{P}$, Toms-Wood A, Wolfe RS: Isolation and properties of a fluorescent compound, factor 420, from Methanobacterium strain M.o.H. J Bacteriol 1972, 112:527-531.

19. Giezen van der M: Hydrogenosomes and mitosomes: conservation and evolution of functions. Eukaryotic Microbiol 2009, 56:221-231.

20. Hampl V, Hug L, Leigh JW, Dacks JB, Lang BF, Simpson AGB, Roger AJ: Phylogenomic analyses support the monophyly of Excavata and resolve relationships among eukaryotic "supergroups". Proc Natl Acad Sci USA 2009, 106:3859-3864

21. Embley TM, Martin W: Eukaryotic evolution, changes and challenges. Nature 2006, 440:623-630.

22. Risgaard-Petersen $N$, Langezaal AM, Ingvardsen S, Schmid MC, Jetten MS, Op den Camp HJ, Derksen JW, Pina-Ochoa E, Eriksson SP, et al: Evidence for complete denitrification in a benthic foraminifer. Nature 2006, 443:93-96

23. Pina-Ochoa E, Hogslund S, Geslin E, Cedhagen T, Revsbech NP, Nielsen LP, Schweizer M, Jorissen F, Rysgaard S, Risgaard-Petersen N: Widespread occurrence of nitrate storage and denitrification among Foraminifera and Gromiida. Proc Natl Acad Sci USA 2010, 107:1148-1153.

24. Atteia A, van Lis R, Gelius-Dietrich G, Adrait A, Garin J, Joyard J, Rolland N, Martin W: Pyruvate:formate lyase and a novel route of eukaryotic ATPsynthesis in anaerobic Chlamydomonas mitochondria. J Biol Chem 2006, 281:9909-9918.

25. Mus F, Dubini A, Seibert M, Posewitz MC, Grossman AR: Anaerobic acclimation in Chlamydomonas reinhardtii anoxic gene expression, hydrogenase induction, and metabolic pathways. J Biol Chem 2007, 282:25475-25486.

26. Meuser JE, Ananyev G, Wittig LE, Kosourov S, Ghirardi ML, Seibert M Dismukes GC, Posewitz MC: Phenotypic diversity of hydrogen production in chlorophycean algae reflects distinct anaerobic metabolisms. J Biotechnol 2009, 142:21-30.

27. Stoeck T, Behnke A, Christen R, Amaral-Zettler L, Rodriguez-Mora MJ, Chistoserdov A, Orsi W, Edgcomb VP: Massively parallel tag sequencing reveals the complexity of anaerobic marine protistan communities. BMC Biology 2009, 7:72

28. Levin LA: Oxygen minimum zone benthos: Adaptation and community response to hypoxia. Oceanography Marine Biol Ann Rev 2003, 41:1-45.
29. Grassineau NV, Nisbet EG, Bickle MJ, Fowler CMR, Lowry D, Mattey DP Abell $P$, Martin A: Antiquity of the biological sulphur cycle: evidence from sulphur and carbon isotopes in 2700 million-year-old rocks of the Belingwe Belt, Zimbabwe. Proc Roy Soc London Series B 2001, 268:113-119.

30. Ueno Y, Yamada K, Yoshida N, Maruyama S, Isozaki Y: Evidence from fluid inclusions for microbial methanogenesis in the early archaean era. Nature 2006, 440:516-519.

31. Dubilier N, Bergin C, Lott C: Symbiotic diversity in marine animals: the art of harnessing chemosynthesis. Nature Rev Microbiol 2008, 6:725-740.

32. Bernhard JM, Habura A, Bowser SS: An endobiont-bearing allogromiid from the Santa Barbara Basin: Implications for the early diversification of foraminifera. J Geophysl Res 2006, 111:G03002

33. Bernhard JM, Buck KR, Farmer MA, Bowser SS: The Santa Barbara Basin is a symbiosis oasis. Nature 2000, 403:77-80

34. Lyons TW, Reinhard CT: An early productive ocean unfit for aerobics. Proc Natl Acad Sci USA 2009, 106:18045-18046.

35. Johnston DT, Wolfe-Simon F, Pearson A, Knoll AH: Anoxygenic photosynthesis modulated Proterozoic oxygen and sustained Earth's middle age. Proc Natl Acad Sci USA 2009, 106:16925-16929.

36. Lyons TW, Anbar AD, Severmann S, Scott C, Gill BC: Tracking euxinia in the ancient ocean: A multiproxy perspective and Proterozoic case study. Ann Rev Earth Planetary Sci 2009, 37:507-534.

37. Mentel M, Martin W: Energy metabolism among eukaryotic anaerobes in light of Proterozoic ocean chemistry. Phil Trans Roy Soc London Series B 2008, 363:2717-2729.

38. Shen B, Dong L, Xiao SH, Kowalewski M: The Avalon explosion: evolution of Ediacara morphospace. Science 2008, 319:81-84.

39. Budd GE: The earliest fossil record of the animals and its significance. Phil Trans Roy Soc London Series B 2008, 363:1425-1434.

40. Dietrich LEP, Tice MM, Newmann DK: The co-evolution of life and Earth. Curr Biol 2006, 16:R395-R400

41. Canfield DE, Poulton SW, Knoll AH, Narbonne GM, Ross G, Goldberg T, Strauss H: Ferruginous conditions dominated later neoproterozoic deep-water chemistry. Science 2008, 321:949-952.

42. Frei R, Gaucher C, Poulton SW, Canfield DE: Fluctuations in Precambrian atmospheric oxygenation recorded by chromium isotopes. Nature 2009, 461:250-253.

43. Cox CJ, Foster PG, Hirt RP, Harris SR, Embley TM: The archaebacterial origin of eukaryotes. Proc Natl Acad Sci USA 2008, 105:20356-20361.

44. Tovar J, León-Avila G, Sánchez LB, Sutak R, Tachezy J, Giezen van der M, Hernández M, Müller M, Lucocq JM: Mitochondrial remnant organelles of Giardia function in iron-sulphur protein maturation. Nature 2003, 426:172-176.

45. Dyall SD, Brown MT, Johnson PJ: Ancient invasions: From endosymbionts to organelles. Science 2004, 304:253-257.

46. Hrdy I, Hirt RP, Dolezal P, Bardonova L, Foster PG, Tachezy J, Embley TM: Trichomonas hydrogenosomes contain the NADH dehydrogenase module of mitochondrial complex I. Nature 2004, 432:618-622

47. Lane N: Life Ascending: The Ten Greatest Inventions of Evolution London: Profile Books 2009.

48. Dunn CW, Hejnol A, Matus DQ, Pang K, Browne WE, Smith SA, Seaver E, Rouse GW, Obst M, Edgecombe GD, et al: Broad phylogenomic sampling improves resolution of the animal tree of life. Nature 2008, 452:745-749.

49. Kristensen RM: An Introduction to Loricifera, Cycliophora, and Micrognathozoa. Integrative Comp Biol 2002, 42:641-651.

50. Heiner I, Kristensen RM: Two new species of the genus Pliciloricus (Loricifera, Pliciloricidae) from the Faroe Bank, North Atlantic. Zoologischer Anzeiger 2005, 243:121-138.

doi:10.1186/1741-7007-8-32

Cite this article as: Mentel and Martin: Anaerobic animals from an ancient, anoxic ecological niche. BMC Biology 2010 8:32. 